\title{
Citrate-Induced Citrate Production and Light-Induced Growth of Blastocladiella emersonii
}

\author{
By E. C. CANTINO AND AIDA GOLDSTEIN \\ Department of Botany and Plant Pathology, Michigan State University, \\ East Lansing, U.S.A.
}

(Accepted for publication 15 September 1966)

\begin{abstract}
SUMMARY
Exogenous citrate induced the growing thin-walled ordinary colourless form (OC cell) of the water fungus Blastocladiella emersonii to produce morecitric acid and, simultaneously, to re-utilize lactic acid liberated previously in one large wave of activity. In the absence of added citrate, release of citric acid was not detectable at the end of the cell's generation time, while production and reutilization of lactic acid did occur, but in very small amounts and in a series of successive waves. An increase in the generation time of an OC cell, previously known to be induced by visible light, was also induced by exogenous citrate in the dark, provided environmental conditions were favourable. Furthermore, increasing amounts of exogenous $\mathrm{CO}_{2}$ increasingly decreased the dark generation time; this inhibition was annulled by light. Some effects of gaseous $\left(\mathrm{CO}_{2} / \mathrm{O}_{2}\right)$ and ionic $\left(\mathrm{Na}^{+} / \mathrm{K}^{+}\right)$balance are also described.
\end{abstract}

\section{INTRODUCTION}

Light-stimulated growth of the ordinary colourless organism (OC cell) of Blastocladiella emersonii was first detected with multiple generation cultures in peptone + yeast-extract + glucose (PYG) medium (Cantino \& Horenstein, 1956). It was later shown (Cantino \& Horenstein, 1959) with synchronized single-generation cultures (SSGC) grown on PYG agar media, whereon it was in part reflected in a bicarbonate and/or $\mathrm{CO}_{2}$ dependent prolongation of the cell's generation time (GT). Finally, both accelerated growth and the GT effect were achieved (Goldstein \& Cantino, 1962) with SSGC in liquid Difco PYG medium supplemented with $5 \times 10^{-3} \mathrm{M}$-phosphate (pH 6.7; PYG-P). However, the liquid medium which yielded the best synchronized cultures, i.e. in which uniform cell suspensions were maintained most consistently with the least effort, was one designed for B. britannica (Horenstein \& Cantino, 1964) and modified for use with $B$. emersori $i$ : namely a Difco PYG medium made up in $1 \cdot 1 \times 10^{-2} \mathrm{M}^{-N_{2}} \mathrm{HPO}_{4}$ and $3 \times 10^{-3} \mathrm{M}$-citric acid (pH 6.6; PYG-PC). But in spite of its advantages, we had difficulty in demonstrating light-induced prolongations of B. emersonii generation time on this medium; the light effects were slight at best and not always reproducible. The purpose of the present report is to show that there was no light effect in PYG-PC medium because citrate substituted for visible light as an inducer of the extended generation time, although modification of the gaseous and ionic balance did permit it to occur even in the presence of citrate. Pertinent terminology, background history, and cultural procedures applicable to this water 
fungus are covered in reviews (Cantino \& Lovett, 1964; Cantino, 1966; Lovett, 1967); past studies of the effects of light on $B$. emersonii were summarized recently (Cantino, 1965).

\section{METHODS}

All synchronized single-generation cultures of OC cells of Blastocladiella emersonii were started with spores and propagated in white light (500 ft.c.) and darkness, at $24^{\circ}$, according to Goldstein \& Cantino (1962) in either peptone + yeast-extract + phosphate medium (PYG-P) or in a similar medium + citrate (PYG-PC), but with numerous modifications as described below. Citric acid was determined by Stern's (1957) method; lactic acid, according to Ryan (1958).

\section{RESULTS}

Comparison of medium without citrate $(P Y G-P)$ and with citrate $(P Y G-P C)$

Uninoculated PYG-P and PYG-PC, autoclaved and non-autoclaved, were illuminated (500 and $2000 \mathrm{ft} . c$.) for $18 \mathrm{hr}$; ultraviolet (u.v.) and visible absorption spectra were taken thereon. Other samples and untreated controls were chromatographed in several solvent systems; papers were examined under u.v. radiation and developed with ninhydrin, ammoniacal $\mathrm{AgNO}_{3}$ and other reagents. No significant chemical differences (other than in citric acid) between the two media were detected which were judged to be important factors in, or which provided additional clues about the reason for, the differences in response of Blastocladiella emersonii to light in these two media.

\section{Comparison of metabolic products in PYG-P and PYG-PC media}

Blastocladiella emersonii was grown in PYG-P and PYG-PC media. Citric acid was not detected in the PYG-P at generation time (GT), while in PYG-PC medium citrate actually increased (Fig. 1); its final concentration in light-grown and dark-grown cultures was about the same. Thus, the presence of exogenous citric acid induced $B$. emersonii to make more of it. Large quantities of lactic acid were also liberated but were re-utilized during the period when citricacid was released (Fig. 2). In PYG-P medium, small amounts of lactic acid were produced and then consumed again, but in at least six successive waves of activity (Fig. 2); by the end of one generation time, little lactate had accumulated.

\section{Effect of aeration rate and $\mathrm{O}_{2} / \mathrm{CO}_{2}$ balance}

Some fifty experiments, in which the aeration rates varied between 1600 and 4200 $\mathrm{ml} . / \mathrm{min}$., led us to conclude that light-induced increases in generation time were small or negligible at low flow rates (i.e. $1500 \mathrm{ml} . / \mathrm{min}$.) but greater at higher flow rates (i.e. $3400 \mathrm{ml} . / \mathrm{min}$.; for example, see controls, shaded $v s$. unshaded bars, Fig. 3). At this higher aeration rate cultures were grown under elevated $\mathrm{O}_{2}$ tensions. The results showed that increased $\mathrm{O}_{2}(a)$, did not affect the generation time of dark grown cells (Fig. 3, controls, shaded, vs. $8 \% \mathrm{O}_{2}$, shaded); (b), at best, slightly augmented the effect of light on the generation time; $(c)$, combined with the removal of $\mathrm{CO}_{2}$ from the air stream, induced an increase in the dark generation time; i.e. the generation time was maximum and about the same for both light-grown and dark-grown organisms. 


\section{Effect of $\mathrm{Na}^{+}$concentration}

The generation time was affected by exogenous $\mathrm{Na}^{+}$(Fig. 4); increasing exogenous $\mathrm{Na}^{+}$from $1.6 \times 10^{-2} \mathrm{M}$ to $2.2 \times 10^{-2} \mathrm{M}$ prolonged the generation time by about $4 \mathrm{hr}$. Below this range, progressive decreases in $\mathrm{Na}^{+}$concentration caused organisms to adhere to the glass vessels; above this range toxicity symptoms appeared.

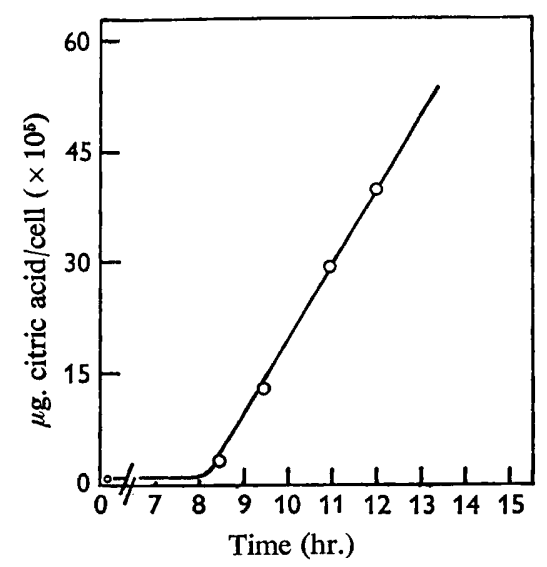

Fig. 1

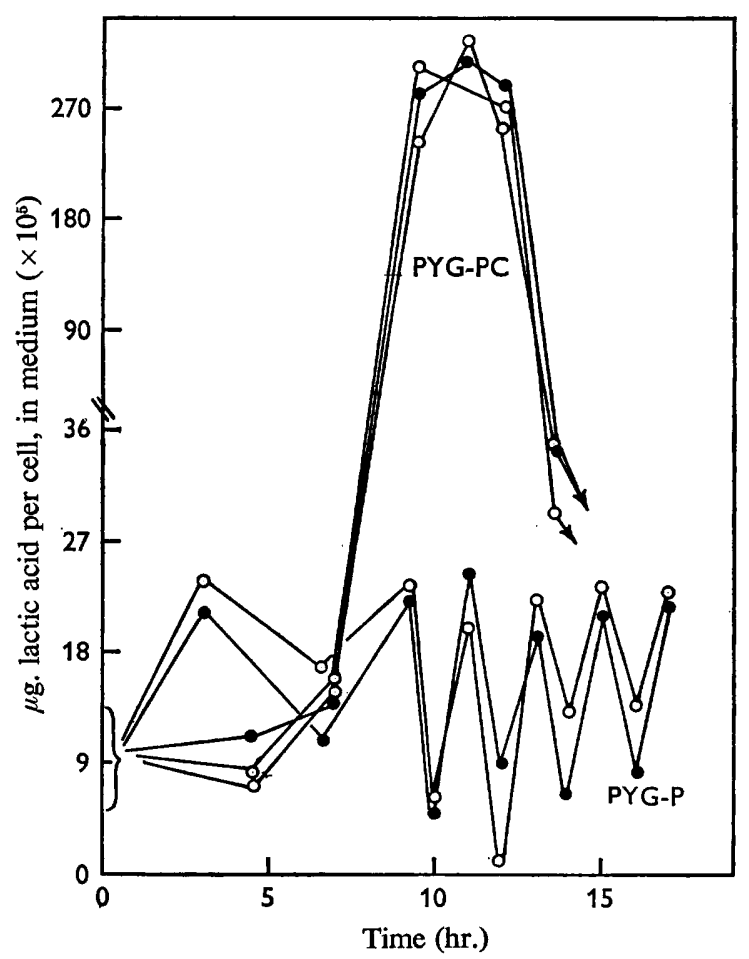

Fig. 2

Fig. 1. Accumulation of citric acid in a SSGC of OC cells in PYG-PC, pH 6.6. Aeration, $3600 \mathrm{ml}$./min.; vol., $600 \mathrm{ml}$; population density, $3 \cdot 1 \times 10^{5} / \mathrm{ml}$. Each point is an average derived from analyses of light- and dark-grown cultures in duplicate.

Fig. 2. Production and re-utilization of lactic acid in SSGC of OC cells in PYG-P and PYGPC, both pH 6.6. Aeration, $3600 \mathrm{ml}$. $/ \mathrm{min}$.: vol. $600 \mathrm{ml}$.; population density, $3 \cdot 1 \times 10^{5} / \mathrm{ml}$. for PYG-PC and $2.3 \times 10^{5} / \mathrm{ml}$. for PYG-P; open circles, light-grown; shaded circles, darkgrown. Similar results for the lactic acid content of spent PYG-PC were published previously (Cantino, 1965); new and more extensive data are shown here for comparison with the analyses of PYG-P.

\section{Effect of cationic balance}

The generation time was also affected by exogenous $\mathrm{K}^{+}$. For example, with phosphate buffer provided as a mixture of $\mathrm{Na}$ and $\mathrm{K}$ salts, $8 \times 10^{-3} \mathrm{M}$ for each cation, light induced increases of generation time of $120 \mathrm{~min}$ and more. However, the OC cells did not discharge their spores. This effect was obtained when $\mathrm{Na}^{+}: \mathrm{K}^{+}$ratios reached unity, and often with ratio value up to 3 ; in such cultures, the final $\mathrm{pH}$ values were no different from the controls containing only $\mathrm{Na}^{+}$. Replacement of all the $\mathrm{Na}^{+}$with $\mathrm{K}^{+}$ (i.e. $1.6 \times 10^{-2} \mathrm{M}$ ) yielded OC cells which were highly vacuolate and grew poorly; they 
were still very small and did not discharge spores even after $28 \mathrm{hr}$ (roughly double the normal generation time). Replacement of $\mathrm{Na}^{+}$with $\mathrm{NH}_{4}{ }^{+}$yielded spherical organisms which grew at more nearly normal rates; but again, these were highly vacuolate and not capable of spore discharge after $28 \mathrm{hr}$.

\section{Effect of $\mathrm{CO}_{2}$ tension}

Blastocladiella emersonii was grown in PYG-PC medium, and the $\mathrm{CO}_{2}$ in the air stream was varied between $0.03 \%$ and $27 \%(\mathrm{v} / \mathrm{v})$. At one generation time, cell shapes were judged subjectively and estimated quantitatively in terms of the ratio cell width: cell length, and cell volumes calculated therefrom. Differences in generation time between light-grown and dark-grown cultures were recorded. Mature OC cells grown

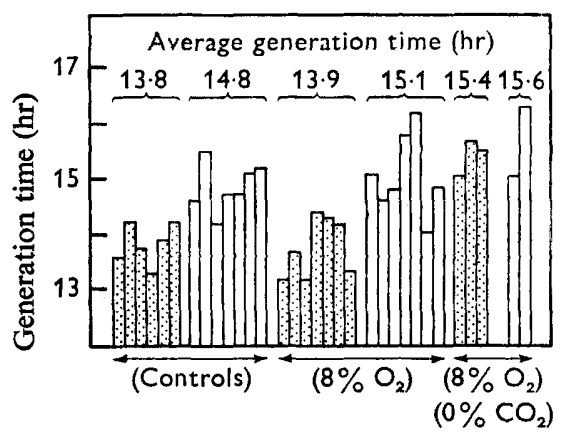

Fig. 3

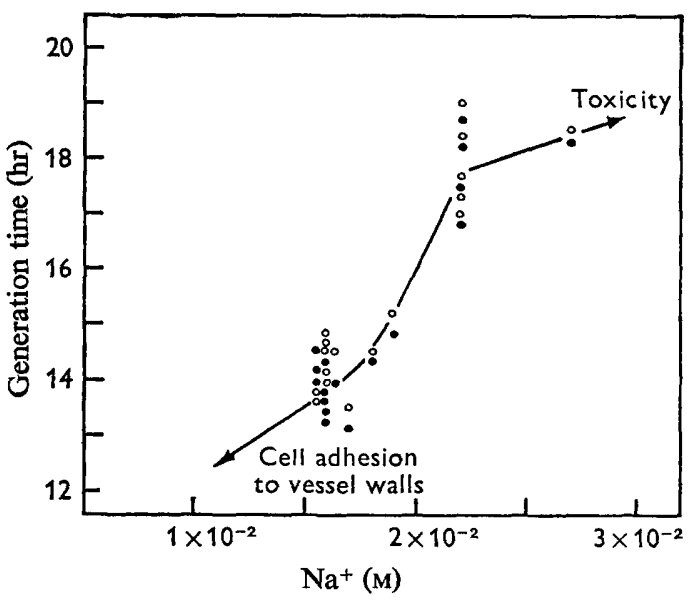

Fig. 4

Fig. 3. Effects of $\mathrm{O}_{2} / \mathrm{CO}_{2}$ balance on the GT and the light-induced increases in GT in SSGC of OC cells in PYG-PC, pH 6.6, using reduced levels of $\mathrm{Na}_{2} \mathrm{HPO}_{4}\left(0 \cdot 8 \times 10^{-2} \mathrm{M}\right.$; i.e. $\mathrm{Na}^{+}$, $\left.1.6 \times 10^{-2} \mathrm{M}\right)$ and citric acid $\left(2.2 \times 10^{-3} \mathrm{M}\right)$. Each bar represents a separate $600 \mathrm{ml}$. culture. Aeration, $3400 \mathrm{ml} . / \mathrm{min}$.; population densities varied between 1.1 and $1.5 \times 10^{5} / \mathrm{ml}$. in the different experiments; unshaded, light-grown; shaded, dark-grown.

Fig. 4. Effect of exogenous $\mathrm{Na}^{+}$concentration on the GT in SSGC of OC cells in $600 \mathrm{ml}$. PYG-PC, pH 6.5-6.6. Each point represents a separate culture. Open circles, light-grown; shaded circles, dark-grown. The $\mathrm{Na}^{+}$level was varied by adjusting the concentration of $\mathrm{Na}_{2} \mathrm{HPO}_{4}$ from $0.8 \times 10^{-2}$ to $1.35 \times 10^{-2} \mathrm{M}$, and citrate from $2 \cdot 2 \times 10^{-3}$ to $3 \times 10^{-3} \mathrm{M}$. Separate control experiments established that the changes in concentrations of phosphate and citrate were not responsible for alterations in GT. Variations in GT at $1.6 \times 10^{-2}$ and $2.2 \times 10^{-2} \mathrm{M}$ $\mathrm{Na}^{+}$(two main clusters of points on graph) were due mainly to the four different flow rates of the aeration stream $(1500,2400,2800$, and $3400 \mathrm{ml} . / \mathrm{min}$.) and the two population densities $\left(1.33 \times 10^{5}\right.$ and $2.6 \times 10^{5}$ cells $/ \mathrm{ml}$.) used in these experiments. Additional note: a serious bottleneck which prevents taking full advantage of a SSGC is the tenacity with which OC cells can sometimes adhere to the glass wall of a culture vessel. Very many experiments, all involving full scale cultures, were done to identify and thereby to circumvent some of the causes involved. These included treatment of glass surface with various agents, and alterations (in various combinations) of $\mathrm{pH}$, aeration rates, spore population densities, and concentrations of $\mathrm{HCO}_{3}{ }^{-}$, total phosphate, $\mathrm{HPO}_{4}{ }^{2-}$, total citrate, citrate ${ }^{3-}, \mathrm{Na}^{+}$and $\mathrm{K}^{+}$. We concluded $(a)$ that the stickiness of cells was seldom if ever due to incorrect concentrations of $\mathrm{HPO}_{4}{ }^{2-}, \mathrm{HCO}_{3}{ }^{-}$, or citrate ${ }^{3-}$, to $\mathrm{pH}$ per se, or to an incorrect balance between total phosphate and total citrate, or between $\mathrm{Na}^{+}$and $\mathrm{K}^{+}$; and $(b)$, that insufficient amounts of total phosphate and/or total $\mathrm{Na}^{+}$were most likely responsible. 
in the dark under $6.7 \%$ and $13 \%(\mathrm{v} / \mathrm{v}) \mathrm{CO}_{2}$ were elongated and only about $1 / 3$ normal size; this inhibitory effect of $\mathrm{CO}_{2}$ on volume was overcome by illumination at $6.7 \%$ (v/v) $\mathrm{CO}_{2}$ but not at $13 \%$ (Table 1 ). Increases in $\mathrm{CO}_{2}$ up to $13 \%$ led to roughly proportional light-stimulated increases in generation time over the values for dark controls; however, the generation times of all light-grown organisms was essentially the same. Thus, the capacity of $\mathrm{CO}_{2}$ to yield light-induced increases in generation time on citrate media was actually due to $\mathrm{CO}_{2}$-induced decreases in the generation time of dark-grown organisms, these decreases being overcome by illumination.

Table 1. Effect of $\% \mathrm{CO}_{2}$ in the air stream on the volume, shape, and GT of $O C$ cells grown in light and darkness on PYG-PC

SSGC volumes were $600 \mathrm{ml}$; ; aeration, $1500 \mathrm{ml}$. $/ \mathrm{min}$.; population density, $1.17 \times 10^{5} / \mathrm{ml}$; initial $\mathrm{pH}, 6.5-6.6$ in all cultures; final $\mathrm{pH}, 6.5-6.6$ for $0.03 \%$ and $0.5 \% \mathrm{CO}_{2} 6.4-6.5$ for $6.7 \% \mathrm{CO}_{2}$, and $6 \cdot 3-6 \cdot 4$ for $13 \% \mathrm{CO}_{2}$. Dark-grown controls without $\mathrm{CO}_{2}$, when adjusted to $\mathrm{pH} 6.3$ and 6.4, did not exhibit decreased GT. Attempts to increase the $\mathrm{CO}_{2} \%$ in the air stream up to $c a .27 \%$ failed due to harmful decreases in $\mathrm{pH}$ to 6.0 and below at GT. Slight increases in phosphate buffer failed to prevent the $\mathrm{pH}$ from dropping too far. Further increases in $\mathrm{Na}_{2} \mathrm{HPO}_{4}$ to more than $2.5 \times 10^{-2} \mathrm{M}$, with or without increases in citric acid to $5 \times 10^{-3} \mathrm{M}$, caused spores to disintegrate (see Fig. 4 and text section on cationic balance). Note that controls in this sort of experiment are particularly critical; the GT depends in part upon aeration rate, population density, $\mathrm{Na}^{+}$concentration, etc., various combinations of which can lead to a GT as high as $19 \mathrm{hr}$ or as low as $14 \mathrm{hr}$.

\begin{tabular}{|c|c|c|c|c|c|c|}
\hline \multirow[b]{2}{*}{$\% \mathrm{CO}_{2}$} & \multicolumn{3}{|c|}{ Light } & \multicolumn{3}{|c|}{ Dark } \\
\hline & $\begin{array}{l}\text { Volume } \\
\left(\mu^{3}\right)\end{array}$ & Width:length & $\begin{array}{l}\mathrm{GT} \\
(\mathrm{hr})\end{array}$ & $\begin{array}{l}\text { Volume } \\
\left(\mu^{3}\right)\end{array}$ & Width:length & $\begin{array}{l}\mathrm{GT} \\
(\mathrm{hr})\end{array}$ \\
\hline $\begin{array}{c}13 \cdot 0 \\
6 \cdot 7 \\
0.5 \\
0.03\end{array}$ & $\begin{array}{r}6.2 \times 10^{4} \\
22.6 \times 10^{4} \\
20.0 \times 10^{4} \\
18.8 \times 10^{4}\end{array}$ & $\begin{array}{c}0.62 \\
0.50 \\
(\text { ca. } 0.8) \\
0.82\end{array}$ & $\begin{array}{l}17 \cdot 0 \\
16 \cdot 9 \\
17 \cdot 1 \\
17 \cdot 1\end{array}$ & $\begin{array}{r}5.9 \times 10^{4} \\
6.0 \times 10^{4} \\
19.0 \times 10^{4} \\
18.3 \times 10^{4}\end{array}$ & $\begin{array}{c}0.68 \\
0.66 \\
(\text { ca. } 0.8) \\
0.84\end{array}$ & $\begin{array}{l}15 \cdot 3 \\
15 \cdot 8 \\
16 \cdot 7 \\
16 \cdot 9\end{array}$ \\
\hline
\end{tabular}

Table 2. Comparison of GT and volume of $O C$ cells grown in light and darkness in $P Y G-P$ and $P Y G-P C$

Growth on PYG-P: values shown are averages for two experiments, each one involving light- and dark-grown cultures in duplicate; population densities were $0.9 \times 10^{5} \mathrm{ml}$. and $2 \cdot 5 \times 10^{5} / \mathrm{ml}$; ; all other details were as described by Goldstein \& Cantino (1962). Growth on PYG-PC: average values are shown for six different experiments, all cultures in duplicate; population density, $1.3 \times 10^{5} / \mathrm{ml}$; aeration rate, $1500 \mathrm{ml} . / \mathrm{min}$.; initial and final $\mathrm{pH}$, $6.55-6.6$ in all instances.

\begin{tabular}{|c|c|c|c|c|}
\hline & \multicolumn{4}{|c|}{ Medium } \\
\hline & \multicolumn{2}{|c|}{ PYG-P } & \multicolumn{2}{|c|}{ PYG-PC } \\
\hline & Light & Dark & Light & Dark \\
\hline $\begin{array}{l}\text { GT (hr) } \\
\text { Cell volume }\left(\mu^{3}\right)\end{array}$ & $\begin{array}{l}17 \cdot 5 \\
19 \cdot 3 \times 10^{4}\end{array}$ & $\begin{array}{l}16.0 \\
8.0 \times 10^{4}\end{array}$ & $\begin{array}{l}17 \cdot 2 \\
18 \cdot 2 \times 10^{4}\end{array}$ & $\begin{array}{l}17 \cdot 1 \\
18.3 \times 10^{4}\end{array}$ \\
\hline
\end{tabular}

Lastly, the generation time and the volume at one generation time of organisms grown without $\mathrm{CO}_{2}$ supplements in light and darkness on PYG-PC medium were compared with organisms similarly grown on PYG-P medium (Table 2). In PYG-P medium, light-induced increases (about $90 \mathrm{~min}$.) in generation time were associated with about twofold light-induced increases in cell volume to about $19 \times 10^{4} \mu^{3}$ (see Goldstein \& Cantino, 1962, for details about this effect). In PYG-PC medium, dark- 
grown organisms displayed the same generation time and volume as those grown in the light in either PYG-PC or PYG-P media, i.e. with or without added citrate. Thus, given suitable $\mathrm{CO}_{2}$ and $\mathrm{Na}^{+}$concentrations, aeration rates, and population densities, exogenous citrate effectively substituted for white light as an inducer of increased size and an extended generation time of an OC cell.

\section{DISCUSSION}

\section{Production and re-utilization of lactate in PYG-P}

Although our studies dealt primarily with the growth of Blastocladiella emersonii in PYG-PC, production and re-utilization of lactate in PYG-P is noteworthy. Its rhythmic appearance and disappearance in successive waves must reflect some endogenous cyclic process during exponential growth of an $\mathrm{OC}$ cell. We suspect that a succession of synchronous nuclear divisions is the cause. The motile spore of this fungus is uninucleate; at maturity, the OC cell derived therefrom can produce a few hundred to perhaps 2000 such spores, depending upon its size at GT. Assuming that a germling becomes binculeate by $3 \mathrm{hr}$ (Turian \& Cantino, 1959), that the doubling time for nuclei lies between one and $2 \mathrm{hr}$, and that nuclear divisions during exponential growth are synchronous, some 8 to 12 replications would suffice to generate the required number of nuclei for the next generation of spores. If metabolism of lactic acid were associated with mitosis, production and re-utilization of lactate in 8 to 12 successive waves might occur; in the present study, 8 waves were detected. But judging from the fact (Turian \& Cantino, 1959) that the nuclear doubling time in an OC germling in PYG is ca. $2 \mathrm{hr}$ in the dark but more like $1.2 \mathrm{hr}$ in the light, and assuming that such differential rates of nuclear reproduction continue throughout ontogeny, more 'lactic acid waves' should have been seen in light-grown cultures than in darkgrown ones. Although the results (Fig. 2) do not show this, analyses were only made at hourly intervals between $9 \mathrm{hr}$ and GT, and even less frequently during the earlier stages in development. A systematic approach with analyses for lactic acid at much more frequent intervals throughout the ontogeny of light- and dark-grown cells should help determine if this notion has validity.

\section{The relation between citrate-induced and light-induced increases in GT of an $O C$ cell}

In 1956 (for all references to Blastocladiella emersonii in this discussion, see Cantino, 1965), we found that a mixture of OC cells of various ages, pre-grown in multiple generation culture and then resuspended in $\mathrm{H}^{14} \mathrm{CO}_{3}^{-}$, consumed more ${ }^{14} \mathrm{C}$ in the light than in the dark and simultaneously accumulated a greater intracellular pool of succinate $-{ }^{14} \mathrm{C}$. From this and other work, it was hypothesized that light-stimulated growth of an OC cell, and the light-induced $\mathrm{CO}_{2}$-dependent extension of its $\mathrm{GT}$, may have been due to increased reductive carboxylation of $\alpha$-ketoglutarate to isocitrate and its cleavage to succinate and glyoxylate. Some in vivo corroboration came from demonstrations that an equimolar mixture of exogenous succinate and glyoxylate did, in fact, substitute for white light by inducing an extended GT of a dark-grown cell. We have now shown that exogenous citrate can also substitute for light by inducing prolongation of the cell's GT, and that-unlike the $\mathrm{HCO}_{3}-1 \mathrm{CO}_{2}$ dependent light induction per se- $\mathrm{CO}_{2}$ is no longer necessary when citrate is provided directly. Assum- 
ing that citrate gives rise to isocitrate within the cell, this observation lends new support for our belief that the light-induced extension of the GT of B. emersonii stems directly or indirectly from a light-induced acceleration of the sequence: $\alpha$-ketoglutarate $+\mathrm{CO}_{2} \rightarrow$ isocitrate $\rightarrow$ succinate + glyoxylate.

In previous reports, we discussed possible connexions between this reaction sequence and other demonstrable effects of light upon Blastocladiella: effects upon its nuclear reproduction and the need for thymidine; upon its capacity for glycine uptake and the latter's relation to exogenous $\mathrm{CO}_{2}$, intracellular isocitratase activity, and DNA production; upon its genesis of protein and polysaccharide during growth, etc. Assuming that the in vivo effect of citrate and of the combination succinate plus glyoxylate have a common basis, there is no need to cover this ground again for it is discussed fully elsewhere.

However our work with citrate does raise unexpected questions for which no clear-cut answers are available. For example, if citric acid substitutes for light by functioning in vivo as the progenitor of succinate and glyoxylate, why does exogenous $\mathrm{CO}_{2}$ depress the GT in the dark when citrate is present? Does $\mathrm{CO}_{2}$ perhaps inhibit entry of lactate via pyruvate into the tricarboxylic acid cycle, or affect decarboxylations therein, or accelerate formation of citrulline via synthesis of carbamyl phosphate? A case could be made for all these possibilities (not from comparative metabolic maps but from what has been established about Blastocladiella's physiology). Why does exogenous citrate induce accumulation of lactic acid, while little if any appears in its absence, only to have it re-utilized just before sporogenesis? And why does exogenous citrate bring about release of additional citrate at this stage in ontogeny? What is the relation of these things to other events associated, in particular, with the terminal stages of ontogeny when an OC cell approaches the end of its development but remains capable of additional light-stimulated growth; events such as the light-induced depression of its D-glucose-6-phosphate: NADP oxidoreductase; the light-induced change in its intracellular distribution of haemoprotein; the sharp rise in its L-glutamine amidohydrolase, associated with rapid incorporation of glutamic acid into protein but almost no equilibration with its amino acid pool; and its very large increase in L-ornithine carbamoyl transferase, decrease in L-arginine ureohydrolase, and rapid uptake of arginine for protein synthesis? And finally, with Wyatt's (1964) provocative discussion of cations and metabolism in mind-especially $\mathrm{K}^{+}$activated, $\mathrm{Na}^{+}$inhibited pathways from phospho-enol-pyruvate and acetate to the Krebs cycle-are the effects of $\mathrm{Na}^{+} / \mathrm{K}^{+}$balances on the GT related to cationic effects upon activity of the OC cell's tricarboxylic acid cycle? It is tempting to speculate about the interrelationships which must exist among the reactions known to occur in Blastocladiella. We shall, however, control this urge in favour of returning to the bench for further work.

This study was supported by research grants from the National Science Foundation and the National Institutes of Health to E.C.C., and by a Pre-doctoral N.I.H. Fellowship to A.G.

\section{REFERENCES}

CANTINO, E. C. (1965). Intracellular distribution of ${ }^{14} \mathrm{C}$ during sporogenesis in Blastocladiella emersonii. Effect of light on hemoprotein. Arch. Mikrobiol. 51, 42.

Cantrno, E. C. (1966). Morphogenesis in aquatic fungi; in The Fungi: an Advanced Treatise, 2, 283, Ed. by G. C. Ainsworth and A. S. Sussman. New York and London: Academic Press. 
Cantino, E. C. \& Horenstein, E. A. (1956). The stimulatory effect of light upon growth and $\mathrm{CO}_{2}$ fixation in Blastocladiella. I. The S.K.I. cycle. Mycologia 48, 777.

CAntino, E. C. \& Horenstein, E. A. (1959). The stimulatory effect of light upon growth and carbon dioxide fixation in Blastocladiella. III. Further studies, in vivo and in vitro. Physiologia Plantarum 12, 251.

Cantino, E. C. \& Lovetr, J. S. (1964). Non-filamentous aquatic fungi: model systems for biochemical studies of morphological differentiation. Advanc. Morphogenesis. 3, 33.

GoldsteIn, AIDA \& CANTINo, E. C. (1962). Light-stimulated polysaccharide and protein synthesis by synchronized, single generations of Blastocladiella emersonii. J. gen. Microbiol. 28, 689.

Horenstein, E. A. \& Cantino, E. C. (1964). An effect of light on glucose uptake by the fungus Blastocladiella britannica. J. gen. Microbiol. 37, 59.

LOVETT, J. S. (1967). Aquatic Fungi: Allomyces and Blastocladiella in Experimental Techniques of Development. Ed. by F. Wilt \& N. Wessells. New York: T. Y. Crowell Co.

RYAN, H. (1958). An improved microdiffusion procedure for the determination of lactic acid. Analyst 83, 528.

STERN, J. R. (1957). Assays of tricarboxylic acids. In Meth. Enzymol. 3, 425.

Turian, G. \& Cantino, E. C. (1959). The stimulatory effect of light on nucleic acid synthesis in the mould Blastocladiella emersonii. J. gen. Microbiol. $21,721$.

WyatT, H. V. (1964). Cations, enzymes and control of metabolism. J. theoret. Biol. 6, 441. 